\title{
Bringing Darwin into the social sciences and the humanities: cultural evolution and its philosophical implications
}

\author{
Stefaan Blancke ${ }^{1,2}$ (D) Gilles Denis $^{3}$
}

Received: 23 January 2018/Accepted: 5 April 2018/Published online: 10 April 2018

(C) Springer International Publishing AG, part of Springer Nature 2018

\begin{abstract}
In the field of cultural evolution it is generally assumed that the study of culture and cultural change would benefit enormously from being informed by evolutionary thinking. Recently, however, there has been much debate about what this "being informed" means. According to the standard view, an interesting analogy obtains between cultural and biological evolution. In the literature, however, the analogy is interpreted and used in at least three distinct, but interrelated ways. We provide a taxonomy in order to clarify these different meanings. Subsequently, we discuss the alternatives model of cultural attraction theory and memetics, which both challenge basic assumptions of the standard view. Finally, we briefly summarize the contributions to the special issue on Darwin in the Humanities and the Social Sciences, which is the result of a collaborative project between scholars and scientists from the universities of Lille and Ghent. Furthermore, we explain how they add to the discussions about the integration of evolutionary thinking and the study of culture.
\end{abstract}

Keywords Cultural evolution · Darwin · Nature and culture · Cognition and culture $\cdot$ Cultural attraction $\cdot$ Epidemiology of representations $\cdot$ Memetics

Stefaan Blancke

st.blancke@gmail.com

1 Department of Philosophy and Moral Science, Ghent University, Ghent, Belgium

2 Department of Cognitive Science, Central European University, Budapest, Hungary

3 CNRS, UMR 8163 - STL - Savoirs Textes Langage, Université de Lille, 59000 Lille, France 


\section{Introduction}

Drawing lessons from nature in order to understand humans and human culture and, at the same time, to prescribe and justify norms and values is a classic theme in Western thinking. The ancient Greeks considered the cosmos not only to denote the universe, but also to mean something like "the good order" (Daston and Vidal 2003; Gottlieb 2000). Passages in the Bible state that the natural order created by God implies a divine moral order (e.g., Romans 1: 20). And the popular concept of the Great Chain of Being did not simply provide a scheme to rank all beings, but was also used to legitimize the societal status quo (Lovejoy 1936).

It is no surprise then that, when Darwin introduced his evolutionary theory, many thinkers seized upon evolution to both understand and justify social and political processes. Their theories came in different shapes and sizes. Spencer and other socalled Social Darwinists believed that Darwin's theory, or at least their interpretation of it, could be used to justify a society in which might made right and thus provided the perfect excuse for England's imperial and colonial aspirations and abuses. Eugenicists, including Charles Darwin's half-cousin Francis Galton, believed that society should intervene in people's reproduction to take over the alleged role of natural selection and thus to generate physically and mentally fit individuals that could contribute to the state, rather than depend on it. In the introduction to the first French translation of The Origin of Species, the translator Clemence Royer captures the high expectations of that period:

It is above all in its moral and humanitarian consequences that Darwin's theory is fruitful [...] This theory contains in itself a whole philosophy of nature and a whole philosophy of humanity [...] It is the universal synthesis of economic laws, social science par excellence [...] We find in it the reason for our instincts, the long-sought-for why of our manners, the mysterious origin of the notion of duty and its vital importance for the conservation of the species. We shall henceforth have an absolute criterion for judging what is good and what is bad from the moral point of view. (Royer 1862, p. lviii)

However, evolution was often invoked to also justify immoral phenomena such as social inequality, racism, and colonialism. The scientific and moral failure of these projects resulted in a popular resentment in the social sciences and the humanities to biological and evolutionary approaches. In recent decades, however, scientists have brought evolutionary biology back into the study of culture, with the intention of creating consilience between the life and the social sciences and the humanities (e.g., Slingerland and Collard 2012; Wilson 1998). These projects have discarded all normative ambitions-although their critics have continued to accuse them of doing exactly that-and set on the ambitious goal of developing evolutionary approaches to human thought, behavior, and culture. New findings in paleontology have shed an exciting new light on our evolutionary history. Comparative studies such as in primatology suggest that human behavior and cognition builds on capacities shared with other animals (Boehm 1999; de Waal 1982, 1996; Goodall 1969; Smuts 1985). Sociobiology, an approach instigated by 
Wilson (1975), sets out to describe and explain (human) group behavior in terms of underlying adaptive strategies. Evolutionary psychologists study how evolved mental structures shape and constrain the preferences and choices of modern humans (Barkow et al. 1992; Barrett 2015; Buss 2005).

These approaches focus mainly on humans as evolved organisms. Another approach, however, treats culture itself as an evolutionary process. This is the study of cultural evolution, which, albeit a tradition with a history, has become tremendously popular in recent years, drawing the attention of students from various disciplines, including psychology, anthropology, primatology, linguistics, biology, philosophy, economics, and sociology. Indeed, most contributions to this topical issue involve discussions of cultural evolutionary themes. To understand the field to which they aim to contribute, let us zoom in a little on the current debates concerning cultural evolution.

\section{Variations of cultural evolution}

The field of cultural evolution is relatively young and as any healthy nascent field of research, there are lively discussions about what is at stake within the field and how the main issues should be approached: What is culture? What is cultural evolution? Is it analogous to biological evolution, and if so, to what extent? To what extent can we use the biological sciences as a source of inspiration to understand cultural change? What is the role of cognition in culture? How should we describe and understand its impact? Can we abstract from cognitive process and focus on the resulting change in cultural items? How can we integrate different perspectives? Within the field there are several "strands" or "camps", between which the water still runs deep, despite recent modest attempts at reconciliation (Acerbi and Mesoudi 2015; Buskell 2016; Claidière and Sperber 2007; Driscoll 2011; Henrich et al. 2008; Heyes 2018; Scott-Phillips 2017; Sterelny 2017; for a critical view, see Morin 2016b; Scott-Phillips et al. submitted). The main strand within cultural evolution started off with works by Cavalli-Sforza and Feldman (1981) and Boyd and Richerson (1985), Richerson and Boyd (2005) that employed models of population genetics to understand the evolution and distribution of cultural traits. However, within the standard approach, the term "cultural evolution" has come to acquire several related, but distinct meanings.

\subsection{Dual-inheritance theory (DIT) or gene-culture evolution}

Humans adapt to their environment at a pace much quicker than biological evolution allows for, which has enabled our species to spread all across the globe and colonize even the harshest places. Cultural evolutionary theorists argue that this exceptional flexibility arises from the fact that we do not merely pass on genes from one generation to the next, but that we also rely on a second, cultural inheritance system by which we pass on information about the environment and how to deal with it over several generations through teaching and imitation. Furthermore, the changes this second inheritance system causes in our behaviour and our 
environment subsequently would exert a selection pressure on the gene frequencies in following generations. The classical example is lactose tolerance that evolved in response to living in herding communities. Another is the evolution of our capacities for culture in tandem with the development of culture (Laland 2017). In other words, through culture humans actively create new environments to which they then adapt in a biological sense. This process is called niche construction. As DIT emphasizes another inheritance system beyond genes, and niche construction puts the focus on the active role of organisms in the creation of the environment to which they adapt (instead of organisms "passively" adapting to a given environment), both notions are thought to contribute to the Extended Evolutionary Synthesis that supplements Standard Evolutionary Theory (Laland 2017; Pigliucci and Müller 2010).

\subsection{Analogy between biological and cultural evolution}

A second strand within the study of cultural evolution assumes a close analogy between biological and cultural evolutionary processes. This means that culture evolves through variation, selection, and the inheritance of the selected items, which allows for the possibility of accumulation, resulting in ever more complex cultural phenomena. The analogy also leads students of cultural evolution to appropriate terms of evolutionary biology to label cultural processes such as "adaptation", "niche construction", and "fitness". Students of standard cultural evolution acknowledge the fact that the analogy is far from perfect. Cultural variation, for instance, is not random or blind, but is often directed at solving particular problems (Mesoudi 2011). Furthermore, they also acknowledge that traits do not need to be copied or replicated reliably, but can be transformed under the influence of universal cognitive mechanisms (Richerson and Boyd 2005). Nevertheless, whatever processes cause cultural change, cultural phenomena such as languages and artifacts appear to evolve in ways that are quite similar to biological evolution. This observation brings us to our third strand of cultural evolution.

\subsection{Using models and methods from evolutionary biology}

According to Lewens (2015), the study of cultural evolution does not depend so much on the idea that cultural and biological evolution are more or less analogous; rather, it means that one uses models and methods from population genetics and other evolutionary life sciences to explicate and understand culture. For instance, cultural items appear to evolve like species, in the sense that one can track their phylogenies and study the transformations they underwent such as in the case of languages, stories, and hand axes (e.g. Cavalli-Sforza and Feldman 1981; Mesoudi 2011; Tehrani 2013). But it does not end here. Mesoudi et al. (2006) have proposed that every discipline within the study of cultural evolution has its counterpart in the field of evolutionary biology. For instance, within the study of macro-evolutionary change, evolutionary anthropology matches with paleobiology, and cultural anthropology with biogeography. In the study of micro-evolutionary processes, psychology and economics find their biological counterpart in experimental 
population genetics, behavioural ecology (and psychology also) in evolutionary ecology, and memetics and neuroscience in molecular genetics. The authors engage in this exercise to demonstrate that "the same tools, methods, and approaches that are used to study biological evolution may productively be applied to the study of human culture, and furthermore, that the structure of a science of cultural evolution should broadly resemble the structure of evolutionary biology." (p. 329) The overall purpose, according to the authors, is "to stimulate a more progressive and rigorous science of culture."

\section{Critiques of standard cultural evolution}

The standard cultural evolutionary approach has not passed without criticisms. In a direct response to the 2006 paper by Mesoudi and colleagues, social anthropologist Tim Ingold questions the added value of transposing biologic approaches to culture. One of his main concerns is the focus on a-contextual cultural traits, in which "agency, power and social relations are but the ephemeral effects of proximate causes whose ultimate source is supposed to lie in capacities and dispositions bequeathed to individuals as an ancestral legacy, independently and in advance of their life in their world" (Ingold 2007, p. 14). Instead, he argues that people construct meaning within particular contexts. Ingold here might be overstretching his criticism because cultural traits can be regarded as stable enough to track their evolution and modifications and to understand their aggregations as populations (Claidière et al. 2014). However, his sentiment that the standard cultural evolutionary approach unduly abstracts from the actual processes that give rise to culture is shared by scientists from within the field of cultural evolution sensu lato. Heyes (2016) labels this abstraction the "phenotypic gambit" (Grafen 1984), a move by which standard cultural evolutionary theorists "black-box" the underlying cognitive processes to focus exclusively on their outcome, namely cultural traits. This strategy may be helpful when one aims at tracing the fate of cultural traits, but it seems insufficient if one wants to explicate and understand the causal processes underlying cultural evolution.

Students of standard cultural evolution are aware that in order to explain and not merely describe cultural change they need to identify and map the factors that exert a causal impact on the distributions of cultural traits. To that end, they have developed a repertoire of possible mechanisms and factors to account for macrolevel cultural phenomena in terms of micro-evolutionary processes. Teaching and imitation explain the stability of cultural information (Laland 2017); heuristics such as the conformity bias and the prestige bias are strategies that tend to guide individuals towards the most "adaptive" cultural forms; and content biases account for individual preferences for particular cultural items over others (Richerson and Boyd 2005). However, opponents of the standard approach claim that these proposals are too coarse (Sperber and Hirschfeld 2007). Instead, teaching and imitation should be broken down into several smaller constitutive processes, a deconstruction that leads to the conclusion that, in themselves, teaching and imitation do not guarantee the stability of cultural traits (Morin 2016a; Scott-Phillips 
2014). Furthermore, heuristics and biases only provide general descriptions of behavioural patterns but, in their turn, require an explanation in terms of underlying cognitive mechanisms (for a general criticism of the use of "vague" heuristics, see Gigerenzer 1996). One phenotypic gambit merely appears to be replaced by several others. As such, an explanation of how processes such as teaching and imitation are supposed to stabilize socially transmitted information remains wanting.

One possible explanation for the fact that students of standard cultural evolution struggle to adequately capture the micro-level processes underlying cultural change could be that they tend to take a top-down approach. They start off with several assumptions and models borrowed from evolutionary biology and subsequently try to squeeze cultural processes and phenomena into these models (Scott-Phillips et al. submitted). The reason might be that they primarily want to make sense of culture from an evolutionary biological perspective: How did humans become cultural? What role did culture play in the evolution of our species? How did culture enable us to adapt to very different and sometimes extremely harsh environments? From that perspective, it makes sense to black-box micro-level processes and zoom out to focus on macro-evolutionary tendencies.

\section{Epidemiology of representations}

If we want to understand and explain culture itself a more appropriate strategy is to investigate how micro-level processes give rise to macro-scale cultural phenomena. This is the focus of the epidemiology of representations or cultural attraction theory (CAT). Students of cultural attraction propose to identify the psychological and ecological factors that exert a causal impact on the formation and distribution of cultural items. They also suggest that the stability of cultural transmission should not be assumed, as standard cultural evolution does, but explained in terms of these factors (Claidière et al. 2014; Morin 2016a; Scott-Phillips et al. submitted; Sperber 1996). One important, but certainly not the only factor, is the evolved human mind. Ceteris paribus, the representations that tap into our intuitions stand the greatest chance of becoming widely distributed and thus cultural (Boyer 1998; Sperber 1996).

As such, the epidemiology of representations is Darwinian in two senses. First, just as standard cultural evolution, it proposes a populational or, as in the words of Lewens (2015), "kinetic" model of culture in the sense that it aims at accounting for macro-level cultural phenomena in terms of the transformations and aggregations of particulate cultural traits (Claidière et al. 2014). Second, the model relies upon an evolutionary understanding of the human mind that students of cultural attraction tend to think of as massively modular (Sperber and Hirschfeld 2007). However, CAT does not depend on biological evolution in any of the three ways that standard cultural does. CAT does not treat culture as a second type of inheritance; nor does it assume that cultural evolution is analogous to biological evolution, or that tools and models from the biological sciences necessarily help us to understand and study culture. 
An epidemiological approach also undermines the popular idea in standard cultural evolution that culture is somehow adaptive. As cultural traits can spread by merely exploiting domain-specific mechanisms, it is more likely that most of them can be regarded as by-products (Sperber 1996). This puts new light on the cui bono question, as memeticists suggest. Memeticists accept the analogy between biological and cultural evolution, but they reject the idea that culture is therefore adaptive. Cultural items ('memes') do not necessarily evolve to perform functions that are beneficial to us, but to themselves. That is, by adapting to the peculiarities of the human mind, they take on forms that merely boost their own reproductive success. As a result, they can be quite damaging to their carriers. It is only because often it is in their own interest to act as a symbiont rather than a parasite that cultural traits appear to be adaptive (Blackmore 2006; Dawkins 1976; Dennett 2017).

\section{Ongoing debates}

The debates revolving cultural evolution will probably continue for some time. At the same time, we will see more and more studies that will help to determine and assess whether and how the different approaches can be reconciled or integrated. Indeed, many of the contributions to the topical collection on Darwin in the Humanities and the Social Sciences can be understood in this regard. They make suggestions as to how concepts from cultural evolution at large can be used to shed new light on the evolution of the human species and on cultural change.

For instance, in his article "From Pleistocene to Holocene: the prehistory of southwest Asia in evolutionary context", archaeologist Trevor Watkins seeks to show how cultural niche construction theory offers the potential to extend the story of human evolution beyond the Pleistocene, through the Neolithic period towards the type of large-scale societies in which we live today. He thus shows the way to the development of a single, long-term, evolutionary account of human history (Watkins, 2017).

The article by linguists Gerhard Schaden and Cédric Patin, "Semiotic systems with duality of patterning and the issue of cultural replicators" sheds light on an ambiguity that arises from a memetic approach to the evolution of language, namely what should be regarded as the linguistic meme: phonemes, the basic units in language that do not carry meaning, or morphemes, the basic units that do. They consider the implications for the evolution of language (Schaden and Patin 2017).

Evolutionary biologist Sylvain Billiard and biological anthropologist Alexandra Alvergne argue in their paper "Stochasticity in cultural evolution: A revolution yet to be achieved", that the field of cultural evolution should pay more attention to the stochastic process of cultural drift. They examine the reasons why drift has not caused as much controversy as in evolutionary biology and discuss the differences and similarities between drift in biological and cultural evolution (Billiard and Alvergne 2017).

In his paper "The evolution of morality and its rollback" philosopher Brian Garvey doubts the hypothesis of unchanged cognitive modules that evolved in the Stone Age to solve problems of social interaction and that generate moral attitudes. 
He develops the original suggestion that these modules experience a phenomenon of evolutionary rollback as a result of legal institutions that enable us to resolve moral issues (Garvey 2018).

The article by theoretical philosopher Jack Vromen, "Ultimate and proximate explanations of strong reciprocity", zooms in on the recent debates about strong reciprocity. By clarifying the distinction between ultimate and proximate explanations, he aims at a better understanding of these debates that also involve discussions about gene/culture coevolution. Vromen argues for conceptual clarity as a means to advance the discussion (Vromen 2017).

However, cultural evolution does not exhaust the ways in which in one can discuss or import Darwin in the Humanities and the Social Sciences. For instance, a long-standing philosophical tradition investigates the implications of Darwinian thinking for classical philosophical disciplines and themes such as epistemology, ethics and the development of our worldview (e.g. Lewens 2007; Ruse 1986; Richards 2000; Stamos 2008). With their paper "Darwin in metaethics: What if the universal acid cannot be contained" philosophers Eleanora Severini and Fabio Sterpetti, join this tradition. They analyze the impact of evolutionary thinking on metaethics with the focus on evolutionary debunking arguments (EDAs). The authors argue that such arguments cannot solely be targeted at moral beliefs on the penalty of epistemic incoherence. Next, they consider whether such incoherence can be avoided by leveling EDAs at beliefs in other domains (Severini and Sterpetti 2017).

The implications of evolutionary thinking for our worldview are discussed in the article "The sociobiology of genes: the gene's eye view as a unifying behaviouralecological framework for biological evolution". Philosophers Alexis De Tiège, Koen Tanghe and Johan Braeckman, and geneticist Yves van de Peer, propose that the gene-centered view of life can be used to integrate gene-selectionism on the one hand, and more organism-centered evolutionary models on the other. They discuss the implications of their proposal for the understanding of human evolution (De Tiège et al. 2017).

As such, the article, and indeed many contributions to our issue, also relate to another philosophical tradition that purports to bring conceptual clarity in scientific discussions and research. In their paper, "The behavioral ecology of irrational behaviors", philosophers of science Philippe Huneman and Johannes Martens analyze the analogy between natural selection and rationality and wonder whether evolutionary biology and economics could be regarded as two aspects of a general science of the optimal allocation of limited resources, which would extend to both organizations and human animals. They examine the lessons to be drawn regarding the claim that a general economic science eventually includes evolutionary biology (Huneman and Martens 2017).

The article by philosopher of science Mathilde Lequin, "Paleoanthropology's uses of the bipedal criterion", focuses on conceptual difficulties concerning the use of bipedalism in paleoanthropology to mark the start of the human lineage. On the basis of a philosophical analysis she offers some suggestions in order to move the current debates concerning bipedalism forward (Lequin 2017). 


\section{Concluding remarks}

The contributions to this issue demonstrate the diversity and richness of the ways in which scholars and scientists import evolutionary thinking and issues into the humanities and the social sciences. As such, each of the articles add both to the development of evolutionary thinking within a particular domain or field, and to integrating the life sciences on the one hand, and the social sciences and the humanities on the other. How this integration should unfold, however, remains food for discussion. Obviously, humans are evolved organisms, but to what extent can we biologize or Darwinize culture? Does using concepts, models and tools from the biological sciences help us to understand cultural phenomena? How do these biological approaches relate to more traditional methods and how can they be reconciled?

These issues are far from settled, but the answers to these questions will have important consequences. The way that we conceive of culture, for instance, will determine how we model it. Can we capture cultural processes by relying on models from population genetics or do we need to develop novel ones from scratch? To what extent can we abstract from the cognitive and communicative processes that underlie cultural change and stability? Or can we only adequately model culture if we take these processes into account? Can we assume that culture is basically adaptive? Or do we need to focus on processes of stochasticity and/or attraction? Building the right models is crucial because only then can we use them to explain and even predict cultural phenomena.

Our choice of model also reflects and determines our beliefs about the causal factors driving cultural change. If one assumes that cultural change is somewhat analogous to biological evolution, then the focus will lie on selection and accumulation of cultural traits, rather than on human minds and their interactions with one another and their environment. In that case, one does not need to look deeper into the peculiarities of human communication or the exact workings of the human mind. It suffices to propose a set of relatively coarse processes, heuristics and biases that are sufficient to give cultural evolution its Darwinian outlook. But if communication and cognition are relevant, then such abstracting models lead us to disregard typical features of culture. Such features might then be more adequately brought to light in concordance with more traditional approaches in the social sciences and the humanities.

Most importantly, however, the debates about cultural evolution, and, therefore, the contributions to this issue, are ultimately about the question what it means to be human. Many scientists and scholars agree that in order to understand ourselves, we need approaches that integrate both the insights that we are evolved organisms and that we have an extraordinary capacity to develop and rely upon culture. Striking the proper balance between biological and cultural approaches will be key to comprehending the cultural animal that we are.

Acknowledgements This topical issue is the result of an international and interdisciplinary collaboration between scholars of the Universities of Lille and Ghent. We would like to thank the members of the DHUSS group for the inspirational and pleasant collaboration, the presenters for making the seminars 
such interesting events, and, of course, the authors for their contributions to this special issue. We also acknowledge the financial support of the universities of Lille and Ghent and of the Maison européenne des sciences de l'homme et de la société "MESHS - Lille Nord de France", which enabled us to organize the seminars. Finally, we want to thank Thom Scott-Phillips and Alberto Acerbi for their helpful comments on the introduction and the editor-in-chief of the History and Philosophy of the Life Sciences, Staffan Müller-Wille, for his patience and valuable advice.

\section{References}

Acerbi, A., \& Mesoudi, A. (2015). If we are all cultural Darwinians what's the fuss about? Clarifying recent disagreements in the field of cultural evolution. Biology and Philosophy, 30(4), 481-503. https://doi.org/10.1007/s10539-015-9490-2.

Barkow, J. H., Cosmides, L., \& Tooby, J. (Eds.). (1992). The adapted mind: Evolutionary psychology and the generation of culture. New York: Oxford University Press.

Barrett, H. C. (2015). The shape of thought: How mental adaptations evolve. Oxford: Oxford University Press.

Billiard, S., \& Alvergne, A. (2017). Stochasticity in cultural evolution: A revolution yet to happen. History and Philosophy of the Life Sciences, 40(1), 9. https://doi.org/10.1007/s40656-017-0173-y.

Blackmore, S. (2006). Why we need memetics. Behavioral and Brain Sciences, 29(4), 349-350.

Boehm, C. (1999). Hierarchy in the Forest: The Evolution of Egalitarian Behavior. Cambridge: Harvard University Press.

Boyd, R., \& Richerson, P. J. (1985). Culture and the evolutionary process. Chicago: University of Chicago Press.

Boyer, P. (1998). Cognitive tracks of cultural inheritance: How evolved intuitive ontology governs cultural transmission. American Anthropologist, 100(4), 876-889.

Buskell, A. (2016). Cultural longevity: Morin on cultural lineages. Biology and Philosophy, 31(3), 435-446. https://doi.org/10.1007/s10539-015-9506-y.

Buss, D. M. (Ed.). (2005). The handbook of evolutionary psychology. Hoboken: Wiley.

Cavalli-Sforza, L. L., \& Feldman, M. W. (1981). Cultural transmission and evolution: A quantitative approach. Princeton: Princeton University Press.

Claidière, N., Scott-Phillips, T. C., \& Sperber, D. (2014). How Darwinian is cultural evolution? Philosophical Transactions of the Royal Society B-Biological Sciences. https://doi.org/10.1098/rstb. 2013.0368.

Claidière, N., \& Sperber, D. (2007). The role of attraction in cultural evolution. Journal of Cognition and Culture, 7(1), 89-111. https://doi.org/10.1163/156853707X171829.

Daston, L., \& Vidal, F. (2003). The moral authority of nature. Chicago: University of Chicago Press.

Dawkins, R. (1976). The selfish gene. Oxford: Oxford University Press.

De Tiège, A., Van de Peer, Y., Braeckman, J., \& Tanghe, K. B. (2017). The sociobiology of genes: the gene's eye view as a unifying behavioural-ecological framework for biological evolution. History and Philosophy of the Life Sciences, 40(1), 6. https://doi.org/10.1007/s40656-017-0174-x.

De Waal, F. (1982). Chimpanzee politics. Power and sex among apes. London: Jonathan Cape.

De Waal, F. (1996). Good natured: The origins of right and wrong in humans and other animals. Cambridge: Harvard University Press.

Dennett, D. C. (2017). From bacteria to Bach and back: The evolution of minds. New York: W.W. Norton.

Driscoll, C. (2011). Fatal attraction? Why Sperber's attractors do not prevent cumulative cultural evolution. The British Journal for the Philosophy of Science, 62(2), 301-322. https://doi.org/10. 1093/bjps/axq032.

Garvey, B. (2018). The evolution of morality and its rollback. History and Philosophy of the Life Sciences. https://doi.org/10.1007/s40656-018-0190-5.

Gigerenzer, G. (1996). On narrow norms and vague heuristics: A reply to Kahneman and Tversky. Psychological Review, 103(3), 592-596.

Goodall, J. (1969). My Friends the Wild Chimpanzees. Washington: National Geographic Society.

Gottlieb, A. (2000). The dream of reason: A history of philosophy from the Greeks to the Renaissance. New York: W.W. Norton. 
Grafen, A. (1984). Natural selection, kin selection and group selection. In J. R. Krebs \& N. B. Davies (Eds.), Behavioural ecology: An evolutionary approach (pp. 62-84). Oxford: Blackwell Scientific Publications.

Henrich, J., Boyd, R., \& Richerson, P. J. (2008). Five misunderstandings about cultural evolution. Human Nature, 19(2), 119-137. https://doi.org/10.1007/s12110-008-9037-1.

Heyes, C. (2016). Blackboxing: social learning strategies and cultural evolution. Philosophical Transactions of the Royal Society B: Biological Sciences. https://doi.org/10.1098/rstb.2015.0369.

Heyes, C. (2018). Enquire within: Cultural evolution and cognitive science. Philosophical Transactions of the Royal Society B-Biological Sciences. https://doi.org/10.1098/rstb.2017.0051.

Huneman, P., \& Martens, J. (2017). The behavioural ecology of irrational behaviours. History and Philosophy of the Life Sciences, 39(3), 23. https://doi.org/10.1007/s40656-017-0150-5.

Ingold, T. (2007). The trouble with 'evolutionary biology'. Anthropology Today, 23(2), 13-17. https://doi. org/10.1111/j.1467-8322.2007.00497.x.

Laland, K. N. (2017). Darwin's unfinished symphony: How culture made the human mind. Princeton: Princeton University Press.

Lequin, M. (2017). Paleoanthropology's uses of the bipedal criterion. History and Philosophy of the Life Sciences, 40(1), 7. https://doi.org/10.1007/s40656-017-0172-z.

Lewens, T. (2007). Darwin. Milton Park: Routledge.

Lewens, T. (2015). Cultural evolution. Conceptual challenges. Oxford: Oxford University Press.

Lovejoy, A. O. (1936). The great chain of being. The history of an idea. Cambridge: Harvard University Press.

Mesoudi, A. (2011). Cultural evolution. How Darwinian theory can explain human culture and synthesize the social sciences. Chicago: Chicago University Press.

Mesoudi, A., Whiten, A., \& Laland, K. N. (2006). Towards a unified science of cultural evolution. Behavioral Brain Sciences, 29(4), 329-347. https://doi.org/10.1017/s0140525x06009083. (discussion 347-383).

Morin, O. (2016a). How traditions live and die. Oxford: Oxford University Press.

Morin, O. (2016b). Reasons to be fussy about cultural evolution. Biology and Philosophy, 31(3), 447-458. https://doi.org/10.1007/s10539-016-9516-4.

Pigliucci, M., \& Müller, G. (2010). Evolution: The extended synthesis. Cambridge: MIT Press.

Richards, J. R. (2000). Human nature after Darwin: A philosophical introduction. London: Routledge.

Richerson, P. J., \& Boyd, R. (2005). Not by genes alone. How culture transformed human evolution. Chicago: University of Chicago Press.

Royer, C.-A. (1862). «Préface du traducteur » in Darwin C., De l'origine des espèces : ou Des lois de progrès chez les êtres organisés, traduit en français sur la troisième édition par Royer C.-A., Paris, Guillaumin.

Ruse, M. (1986). Taking Darwin seriously: A naturalistic approach to philosophy. Oxford: Blackwell.

Schaden, G., \& Patin, C. (2017). Semiotic systems with duality of patterning and the issue of cultural replicators. History and Philosophy of the Life Sciences, 40(1), 4. https://doi.org/10.1007/s40656017-0167-9.

Scott-Phillips, T. C. (2014). Speaking our minds. Why human communication is different, and how language evolved to make it special. London: Palgrave MacMillan.

Scott-Phillips, T. C. (2017). A (Simple) experimental demonstration that cultural evolution is not replicative, but reconstructive-and an explanation of why this difference matters. Journal of Cognition and Culture, 17(1-2), 1-11. https://doi.org/10.1163/15685373-12342188.

Scott-Phillips, T. C., Blancke, S., \& Heintz, C. (submitted). Four misunderstandings about cultural attraction.

Severini, E., \& Sterpetti, F. (2017). Darwinism in metaethics: What if the universal acid cannot be contained? History and Philosophy of the Life Sciences, 39(3), 27. https://doi.org/10.1007/s40656017-0154-1.

Slingerland, E., \& Collard, M. (Eds.). (2012). Creating consilience: Integrating the sciences and the humanities. Oxford: Oxford University Press.

Smuts, B. (1985). Sex and friendship in baboons. New York: Aldine Pub. Co.

Sperber, D. (1996). Explaining culture. A naturalistic approach. Oxford: Blackwell.

Sperber, D., \& Hirschfeld, L. (2007). Culture and modularity. In P. Carruthers, S. Laurence, \& S. P. Stich (Eds.), The innate mind: Culture and cognition (pp. 149-164). Oxford: Oxford University Press.

Stamos, D. N. (2008). Evolution and the big questions. Sex, race, religion and other matters. New York: Henry Holt and Company. 
Sterelny, K. (2017). Cultural evolution in California and Paris. Studies in History and Philosophy of Science Part C: Studies in History and Philosophy of Biological and Biomedical Sciences, 62, 42-50. https://doi.org/10.1016/j.shpsc.2016.12.005.

Tehrani, J. J. (2013). The phylogeny of little red riding hood. PLOS ONE, 8(11), e78871. https://doi.org/ 10.1371/journal.pone.0078871.

Vromen, J. (2017). Ultimate and proximate explanations of strong reciprocity. History and Philosophy of the Life Sciences, 39(3), 25. https://doi.org/10.1007/s40656-017-0151-4.

Watkins, T. (2017). From pleistocene to Holocene: the prehistory of southwest Asia in evolutionary context. History and Philosophy of the Life Sciences, 39(3), 22. https://doi.org/10.1007/s40656-0170152-3.

Wilson, E. O. (1975). Sociobiology: The new synthesis. Harvard: Harvard University Press.

Wilson, E. O. (1998). Consilience: The unity of knowledge. New York: Knopf. 